\title{
Clinical Outcome Following Treatment with Clavicular Hook Plate
}

\section{R Varrall*}

Cumberland Infirmary, Carlisle, UK

\begin{abstract}
Hook plates are used to treat acromio-clavicular joint dislocations and lateral clavicle fractures. Our study looked at patient outcome following treatment with a Synthes clavicular hook plate.

Method: Medical notes review and telephone interview of patients treated with a clavicular hook plate between 2003 and 2009 at Airedale General Hospital. Modified constant score calculated looking at pain, range of movement, power and functional level, and general comments recorded.

Results: Total of fifteen patients treated with hook plates, unable to contact two patients, three notes unavailable. Of remaining ten patients (M:F; 7:3), six were for lateral clavicle fractures, three for ACJ dislocation and one not recorded. One plate was still in situ. Follow up after plate removal ranged from 0-79 months, mean 22 months. Only complication was a fatigue fracture next to the plate prior to removal. Modified constant score, out of 80 , had a mean of 78 (range 25-80). Patients reported problems with pain and reduced range of movement whilst the hook plate was in situ, with some pain remaining after removal, particularly affecting their sleep.
\end{abstract}

Conclusion: It is previously documented that hook plates are an effective way of treating ACJ dislocations and lateral clavicle fractures, however patients should be appropriately counselled of the likely discomfort whilst in situ which occasionally persists after removal.

Keywords: Clavicle; Fracture; Acromio-cavicular joint; Hook plate

\section{Introduction}

Hook plates are an effective treatment option for acromioclavicular joint dislocation or lateral clavicle fractures to improve shoulder function and prevent non-union [1-5].

There are a number of treatment options used in the management of lateral clavicle fractures and acromio-clavicular joint dislocations, including conservative treatment, $\mathrm{K}$-wiring across the fracture or the acromio-clavicular joint, securing with tension band wiring, modified Weaver-Dunn procedure, or clavicular plate. All have different risks and benefits and there is not a clear front runner [6,7].

The hook plate is a pre-contoured plate in a variety of sizes with a hook of varying depths to suit different patients' anatomy. The hook is situated posteriorly, hence it is a right or left sided implant. Various companies make the implant, including the AO Synthes system.

The hook plate system enables early rotational mobility of the shoulder. It has been shown to have a favourable outcome in a number of studies $[1,4,8]$ but also has documented complications such as nonunion, infection and acromial osteolysis $[2,3,5]$.

The hook plate is used for Neer Type II lateral clavicle fractures, and acromio-clavicular joint dislocations Rockwood grade III to V. It is recommended by the manufacturer that the plate should be removed once the fracture has united to prevent impingement and acromial osteolysis. It should also be used cautiously in the older patient [6].

The Synthes hook plate has been used at Airedale Hospital for six years. Our study is to look at patient outcome following treatment with a hook plate.

\section{Method}

This was a retrospective study. Patients who received a hook plate for treatment of a lateral clavicle fracture or acromio-clavicular joint dislocation at Airedale Hospital between 2003 and 2009 were identified using theatre logbooks, coding and the hospital radiology system.
The inclusion criteria were any patients who had a clavicular hook plate inserted during the aforementioned period (total 15 patients). Exclusion criteria were inability to make contact with the patient $(2$ patients) and inability to access their notes (3 patients). The remaining ten patients' notes were reviewed for mechanism of injury, diagnosis, operation details and complications.

The patients were contacted for a telephone interview. We used a modified Constant score looking at pain (out of 15), range of movement - forward flexion, abduction, internal rotation, external rotation (out of 10 each), activity level (out of 20) and perceived power (out of 5), giving a total out of 80 (Table 2). Patients were also asked for their general comments.

\section{Results}

There were three patients with acromio-clavicular joint dislocation, one each of Rockwood grade II, III and IV. Six patients had lateral clavicle fractures. One patient's notes did not state the diagnosis and there were no available X-ray images. Follow-up time ranged from 0-79 months (mean 22 months) after removal of the hook plate (Table 1).

Of the two uncontactable patients, both hook plates were inserted for clavicle fractures, with one still in situ. There were seven male patients and three female patients. Four injuries were of the right clavicle and six were of the left. The mechanisms of injury included three falls, two motorcycle accidents, three pedestrians hit by cars and two bicycle accidents.

*Corresponding author: C R Varrall, MBBS, Castle Farm House, Backworth Newcastle-upon-Tyne, NE27 OAU, UK, E-mail: ruth@varrall.com

Received May 21, 2012; Accepted October 27, 2012; Published October 29 2012

Citation: Varrall CR (2012) Clinical Outcome Following Treatment with Clavicular Hook Plate. J Trauma Treat 1:150. doi:10.4172/2167-1222.1000150

Copyright: (c) 2012 Varrall CR. This is an open-access article distributed unde the terms of the Creative Commons Attribution License, which permits unrestricted use, distribution, and reproduction in any medium, provided the original author and source are credited. 
Page 2 of 3

\begin{tabular}{|c|c|c|c|c|c|c|c|c|c|}
\hline Age at insertion & $\begin{array}{l}\text { Duration of plate } \\
\text { (months) }\end{array}$ & $\begin{array}{l}\text { Time since plate } \\
\text { removal (months) }\end{array}$ & Side & Diagnosis & Pain (15) & $\begin{array}{c}\text { Activities + } \\
\text { positioning (20) }\end{array}$ & $\begin{array}{c}\text { ROM } \\
(40)\end{array}$ & $\begin{array}{l}\text { Power } \\
\text { (5) }\end{array}$ & $\begin{array}{l}\text { Modified Constant } \\
\text { score }(80)\end{array}$ \\
\hline 443 & 4 & 49 & L & $\#$ & 15 & 20 & 40 & 5 & 80 \\
\hline $17 \lesssim$ & 6 & 34 & $\mathrm{R}$ & $\#$ & 15 & 20 & 40 & 5 & 80 \\
\hline 16 우 & 4 & 22 & $\mathrm{~L}$ & $\#$ & 15 & 20 & 40 & 5 & 80 \\
\hline 69 우 & 2 & 79 & L & $\#$ & 15 & 20 & 38 & 4 & 77 \\
\hline $51 \lesssim$ & 2 & 23 & L & Gd3 ACJ & 10 & 16 & 40 & 5 & 76 \\
\hline 51 우 & 8 & 15 & $\mathrm{R}$ & \# & 10 & 20 & 40 & 5 & 75 \\
\hline $14 \lesssim$ & 2 & 21 & $\mathrm{R}$ & $\#$ & 15 & 20 & 40 & 5 & 80 \\
\hline $42{ }^{\pi}$ & 6 & 10 & $\mathrm{~L}$ & Gd2 ACJ & 15 & 18 & 40 & 5 & 78 \\
\hline $37 \sigma^{\pi}$ & 13 & 76 & $\mathrm{R}$ & $?$ & 15 & 18 & 40 & 5 & 78 \\
\hline $31 \delta$ & 5 & 0 & $\mathrm{~L}$ & Gd4 ACJ & 5 & 6 & 10 & 4 & 25 \\
\hline
\end{tabular}

Table 1: Patient scores following telephone interview.

\begin{tabular}{|c|c|c|}
\hline Pain Score & Activities & Positioning \\
\hline no pain 15 & unaffected sleep 2 & waist 2, \\
\hline mild 10 & full work 4 & xiphoid 4 \\
\hline moderate 5 & full recreation 4 & neck 6 \\
\hline \multirow[t]{2}{*}{ severe 0} & & top of head 8 \\
\hline & & above head 10 \\
\hline \multicolumn{3}{|c|}{ Range of movement } \\
\hline Forward flexion and abduction & External rotation & Internal rotation \\
\hline $\begin{array}{l}0-30^{\circ}=0,31-60^{\circ}=2,61-90^{\circ}=4,91-120^{\circ}=6,121-150^{\circ}=8 \\
151-180^{\circ}=10\end{array}$ & $\begin{array}{l}2 \text { ach for behind head, elbow forward; behind head, } \\
\text { elbow back; top of head, elbow forward; top of head, } \\
\text { elbow back; full elevation from top of head }\end{array}$ & $\begin{array}{l}\text { Position of dorsum of hand. } \\
\text { Lateral thigh } 0 \text {, buttock } 2 \text {, lumbosacral junction } 4 \text {, } \\
\text { waist } 6, T 12 \text { vertebra } 8 \text {, interscapular } 10\end{array}$ \\
\hline \multicolumn{3}{|c|}{ Power } \\
\hline
\end{tabular}

Table 2: Modified Constant Scoring System.

One patient's plate was still in situ when we contacted him. This was inserted for grade IV acromio-clavicular joint dislocation five months ago. He described moderate pain; it was always uncomfortable and affected his sleep as he was unable to lie on the operated side. $\mathrm{He}$ was unable to return to work currently. He had reduced power $4 / 5$ and decreased range of movement in all directions (forward lexion $50^{\circ}$, lateral flexion $50^{\circ}$, external rotation to behind head and internal rotation to buttock) and is waiting for the plate to be removed.

Of the remaining nine patients, seven patients have no pain and two patients describe mild pain. Two patients' sleep was still affected by lying on the operated side. One patient was unable to return to his previous occupation as a bricklayer due to pain across the top of his shoulder after plate removal, however all other patients had returned to previous employment or activity level.

All but one patient have a full range of movement and normal power. This patient's treatment was complicated by a fatigue fracture next to the plate. She had reduced internal rotation to T12 and 4/5 power on that side.

The modified constant score, out of 80 , had a mean of 78 (range 25-80).

When asked for general comments on their treatment with a clavicular hook plate, patients reported the following:

o Uncomfortable, can't stretch, can't sleep on that side as plate in situ

o Lots of pain when plate in situ, painful if I lie on that side now (six years following removal)

o Have to sleep on front now (ten months following removal)

o Pain worse after insertion, improved after removal but still mild o Ache at top of shoulder like carrying a heavy bag, not improved with removal two years ago

o Couldn't lie on that side when plate in situ

o Tender for a year after removal, now fine

o Very stiff initially for two years after removal, improved with yoga

\section{Discussion}

Although clavicular hook plating is previously documented $[1,4,8]$ to be an effective way of treating a lateral clavicle fracture or acromio-clavicular joint dislocation, our study revealed that patient satisfaction with this treatment, particularly when the plate was in situ, is low. Patients commented that it was often more painful than preoperatively, and that pain persisted following plate removal in some cases. Sleep seems to be most problematic with $20 \%$ of patients unable to lie on that side, even after removal of the plate. This dissatisfaction remained despite most patients ultimately gaining an excellent range of movement.

In one case, the problems with pain had wider reaching consequences, as the patient was unable to return to work as a builder. Surgeons should therefore take a careful occupational history before considering treatment with a clavicular hook plate to ensure informed consent is gained.

We noticed that plates remained in situ for between 2 and 13 months despite manufacturer recommendations that the implant be removed once the fracture has united at around 3 months. This could be due to a lack of awareness of junior doctors seeing patients in the fracture clinic post-operatively and therefore careful post-operative notes and planning are required. Patients also need regular X-ray follow-up so the plate can be removed at the earliest opportunity to limit associated 
morbidity. There was only one complication (10\%), a fatigue fracture next to plate in the oldest patient. There were no cases of infection or non-union. In view of our small numbers we were not able to do any valid statistical testing on the data we collected. However, there does not seem to be any particular pattern to predicting which patients will have a lower modified Constant score ultimately. The modified Constant score did not seem to correlate well with patient feedback either, in that some patients with no pain, full range of movement and a return to normal activities reported low satisfaction overall. This highlights that a good perceived outcome from a surgeon's point of view may differ from that of the patient.

We acknowledge that our study has a number of limitations. It is retrospective and only has 10 subjects. Interviews were by telephone rather than in person and we therefore had to modify the Constant Shoulder score. No X-ray review was undertaken to assess radiological outcome following the hook plate, and we therefore also could not look for osteolysis as a complication. There is no comparison between patients treated with hook plates and either conservative management or alterative operative interventions.

\section{Conclusion}

Clavicular hook plate fixation is previously proven to be an effective option for fixing lateral clavicle fractures or acromio-clavicular joint dislocations. We recommend removing the plate as soon as the fracture has united to limit the morbidity associated with the plate being in situ. Patient selection is very important taking into account the age, expectations and occupation of the patient.
It is most important that when undergoing the consent process, patients are made aware that whilst the plate is in situ it is often uncomfortable and this may persist after removal.

\section{References}

1. Meda PV, Machani B, Sinopidis C, Braithwaite I, Brownson P, et al. (2006) Clavicular hook plate for lateral end fractures:- a prospective study. Injury 37 277-283.

2. Charity RM, Haidar SG, Ghosh S, Tillu AB (2006) Fixation failure of the clavicular hook plate: a report of three cases. J Orthop Surg (Hong Kong) 14: 333-335.

3. Jeevan Chandrasenan, Sachin Badhe, Timothy Cresswell, Joe De Beer (2007) The Clavicular Hook Plate: Consequences in Three Cases. European Journal of Trauma and Emergency Surgery 33: 557-559.

4. Flinkkilä T, Ristiniemi J, Lakovaara M, Hyvönen P, Leppilahti J (2006) Hookplate fixation of unstable lateral clavicle fractures: a report on 63 patients. Acta Orthop 77: 644-649.

5. Tambe AD, Motkur P, Qamar A, Drew S, Turner SM (2006) Fractures of the distal third of the clavicle treated by hook plating. Int Orthop 30: 7-10.

6. Amarasekera S, Davey KJ (2006) Clavicle hook plate - is it the definitive intervention? A retrospective analysis of clavicle hook plate fixation. Journal of Bone and Joint Surgery 88B: 315

7. Banerjee R, Waterman B, Padalecki J, Robertson W (2011) Management of distal clavicle fractures. J Am Acad Orthop Surg 19: 392-401.

8. Renger RJ, Roukema GR, Reurings JC, Raams PM, Font J, et al. (2009) The clavicle hook plate for Neer type II lateral clavicle fractures. J Orthop Trauma 23: $570-574$ 